\title{
Time to deliver patient centred care
}

We must harness the energy, insight and expertise of patients, carers, and the communities that support them to help drive change

\author{
Tessa Richards senior editor, patient partnership ${ }^{1}$, Angela Coulter director of global initiatives and \\ Spotlight guest editor ${ }^{2}$, Paul Wicks vice president of innovation and Spotlight guest editor ${ }^{3}$ \\ ${ }^{1}$ The BMJ, London WC1H 9JR, UK; ${ }^{2}$ Informed Medical Decisions Foundation, Boston, USA; ${ }^{3}$ PatientsLikeMe, Cambridge, MA, USA
}

Patient centred care is central to the mission of healthcare, yet traditionally neither patients nor the public have had the power to shape the services they use and pay for, or define their value. ${ }^{1}$ As a result, many patients find services difficult to navigate, disempowering, burdensome, and seemingly designed to frustrate. ${ }^{2}$

There have been repeated calls to enlist patients' help to reform systems poorly geared to meet current health challenges, subject to political meddling, and permeated by competing interests that fuel overdiagnosis and overtreatment ${ }^{3-5}$ UK and US policy supports person centred care and shared decision making, ${ }^{67}$ and the World Health Organization champions it. We know it improves the quality of care and promotes appropriate use of services. ${ }^{8}$ There is broad agreement on what it is, ${ }^{9}$ and guidance on how to deliver it. ${ }^{10} 11$ The challenge remains one of overcoming "system" inertia and paternalism.

This Spotlight series, developed in partnership with members of The BMJ's patient advisory panel and enlivened by a roundtable debate and interviews with discussants in the US, India, Uganda, Equador, and mainland Europe, seeks to inform, inspire, and spur change.

There is wide support for measuring and incentivising person centred care. ${ }^{12}{ }^{13}$ In New South Wales districts are competing to provide it, with promising results. ${ }^{14}$ Robert et al describe how to codesign services with patients and carers. ${ }^{15}$ And the familiar message that strong leaders who ensure that all staff are responsible for patient partnership and person centred care can transform failing services fast is repeated in a podcast. ${ }^{16}$

It's agreed that feedback from patients and their families should be more rigorous and used to inform practice, not merely collated for research. ${ }^{17}$ Nelson illustrates the value of systematically collecting information on patients concerns and priorities at the point of care and using outcome measures that they identify. ${ }^{18}$

\section{Care should promote self management, not dependency}

The rising number of people living with long term conditions, multimorbidity, and frailty requires services to be radically redesigned, and Eaton and colleagues highlight new approaches. ${ }^{19}$ These have to be based on a better understanding of what people need from health and social services, and patients can be crystal clear about this. ${ }^{20}$

People who live with long term conditions are already in charge of their own health and if given the chance, willing to take on even complex management tasks. ${ }^{21}$ But it won't happen without the development of the science of care and support planning, better training of front line clinical staff, and inclusion of patients and carers in multidisciplinary teams. ${ }^{22}$ Tailored support reduces dependency and can help the disadvantaged most. ${ }^{23}$ All services should keep the burden of treatment on patients as low and "minimally disruptive" as possible. ${ }^{24}$

We also need to find better ways to listen to patients and ensure their voice is included and heard in medical forums. Better conversations are also core to realising shared decision making based on individual priorities and preferences. The quality of the information on which joint decisions are based needs to be improved too, and innovative decision aids hold promise..$^{25} 26$

\section{Digital revolution is changing traditional roles}

The democratisation of health information, use of social media, rapid growth of networked patient communities, and new technologies have changed the landscape and provide new opportunities to harness the energy and expertise of patients. Clinicians and medical educationalists must catch up. Empowered, engaged e-patients are growing a social movement and spearheading a shift in roles "as profound as women's 
liberation," says de Bronkart, who suggests we need a new science to understand and optimise the role of the patient. ${ }^{27}$ Although the global flow of information has transformed many aspects of our lives, it has bypassed chunks of the health sector and it is still hard to get full access to personal health records. But there is welcome news on how the international move to open notes to patients is gaining momentum. ${ }^{28}$ However, it needs to go beyond giving people "viewing rights." Montori emphasises that indigestible records must be made more useful to patients (and doctors) and foster communication, not substitute for it. ${ }^{29}$

In an unequal world the issue for billions of people is not whether care is patient centred but whether it is available at all, its poor quality, and its high cost. Anger and disillusionment are spurring change, however, and Jain provides illuminating examples of how patients' rights are being advanced by effective advocacy in India, and local communities are holding the health sector to account. ${ }^{30}$

It's time to get real about delivering person centred care. It's not a panacea for all of medicine ills, but we should not underestimate its contribution to tackling them. Working collaboratively and sharing decisions about care, services, and research is challenging. It requires a sea change in mindset among health professionals and patients alike. But its rewards are rich and reaped mutually.

Competing interests: See www.bmj.com/about-bmj/advisory-panels/ patient-panel-members.

Listen to the podcast on thebmj.com.

This Spotlight was supported by DNV GL. The articles were commissioned and peer reviewed according to the The BMJ's normal processes.

Provenance and peer review: Not commissioned; not externally peer reviewed.

1 Crisp N. Patient power needs to be built on strong intellectual foundations. BMJ 2012;345:e6177.

2 Mitchell D. Try my new NHS helpline. You have nothing to lose but the will to live. Observer 2015 Jan 11. www.theguardian.com/commentisfree/2015/jan/11/new-nhs-helpline-youvenothing-to-lose-but-the-will-to-live.
3 Richards T, Montori V, Godlee F, Lapsely P, Paul D. Let the patient revolution begin. BMJ 2013;346:f2614.

4 Hodgkin P, Taylor J. Power to the people: what will bring about the patient centred revolution? BMJ 2013;347:f6701

5 Glasziou P, Moynihan R, Richards T, Godlee F. Too much medicine; too little care. BMJ 2013;347:f4247.

6 Department of Health. Equity and excellence: liberating the NHS. Cm 7881. DH, 2010.

7 US Government. Patient Protection and Affordable Care Act (PPACA) 2010 HR3590.

8 Stacey D, Legare F, Col NF, Bebbett CL, Eden KB, Holmes-Rovner M, et al. Decision aids for people facing health treatment or screening decisions. Cochrane Database Syst Rev 2014;1:CD001431.

9 Health Foundation. Person-centred care made simple. 2014. www.health.org.uk publications/person-centred-care-made-simple.

10 Fahey T, Nicliam B. Assembling the evidence for patient centred care. BMJ 2014;349:g4855

11 Gordon and Betty Moore Foundation. A roadmap for patient and family engagement in healthcare practice and research: practical strategies for advancing engagement. 2014.

12 Greenfield G. GPs should be rewarded for patient experience to encourage a person centred NHS. BMJ 2014;349:g6422.

13 Parish E. BMJ roundtable debate: How can we get better at providing patient centred care? BMJ 2015;350:h412.

14 Luxford K, Newell S. New South Wales mounts "patient based care" challenge. BMJ 2015;350:g7582.

15 Robert G, Cornwell J, Locock L, Purushotham A, Sturmey G, Gager M. Patients and staff as codesigners of healthcare services. BMJ 2015;350:g7714.

16 Richards T. Listen to patients first. BMJ 2014:349:95765.

17 Coulter A, Locock L, Ziebland S, Calabrese J. Collecting data on patient experience is not enough: they must be used. BMJ 2014;348:g2225.

18 Nelson EC, Eftimovska E, Lind C, Hager A, Wasson JH, Lindblad S. Patient reported outcome measures in practice. BMJ 2015;350:g7818.

19 Eaton S, Roberts S, Turner T. Delivering person centred care in long term conditions. BMJ 2015;350:h181.

20 Silverstein A. What I need to self manage my care. BMJ 2015;350:h248.

21 Barnes $T$, Winfrow M, Laboi $P$, Wilkie M. Supporting patient independence in long term haemodialysis. BMJ 2015;350:h252.

22 Frosch D. The patient is the most important member of the team. BMJ 2015;350:g7767.

23 Coulter A, Locock L, Ziebland S, Calabrese J. Collecting data on patient experience is not enough: they must be used. BMJ 2014;348:92225.

24 Hibbard JH, Greene J. What the evidence shows about patient activation: better health outcomes and care experiences; fewer data on costs. Health Aff 2013;32:207-14.

25 Mair FS. Thinking about the burden of treatment. BMJ 2014;349:g6680.

26 Agoritas T, Heen AF, Brandt L, Alonso-Coello P, Kristiansen A, AkI EA, et al. Decision aids that really promote shared decision making: the pace quickens. BMJ 2015;350:g7624

27 De Bronkhart D. From patient centred to people powered: autonomy on the rise. BMJ 2015;350:h148.

28 Walker J, Meltsner M, Delbanco T. US experience with doctors and patients sharing clinical notes. BMJ 2015;350:g7785.

29 Montori V, Tabini CC. Opening access to the medical record calls for other reforms. BMJ 2015;350:h271.

30 Jain A. Patient communities reform healthcare in India. BMJ 2015;350:h225.

Cite this as: BMJ 2015;350:h530

(c) BMJ Publishing Group Ltd 2015 